\title{
Hospital Information Sharing based on Social Network Web
}

\author{
Yudhistira Adi Nugraha \\ Paturusi \\ Departement of Information \\ Technology Udayana University \\ BALI, INDONESIA
}

\author{
I Made Sukarsa \\ Departement of Information \\ Technology Udayana University \\ BALI, INDONESIA
}

\author{
I Gusti Made Arya \\ Sasmita \\ Departement of Information \\ Technology Udayana University \\ BALI, INDONESIA
}

\begin{abstract}
Hospital is a public health service institution. There are many social interactions in Hospital, between medical patients, doctors, nurses, and other people in Hospital. Social interaction in that community can be managed into a social network website. Social network website that designed not only for connected user in community, but also electronic medical record (EMR) and wiki added too. The web designed to combine little part of hospital management information system (Electronic Medical Records) and social network web. In Addition, web which designed able to handle data from many hospitals with numerous user into one web. It all became the new value of this research. The result is a design of social network website for hospital community that able to handle data from many hospitals.
\end{abstract}

\section{General Terms}

Design of Hospital information sharing based on social network web

\section{Keywords}

Social network Web, Electronics Medical Records (EMR), Web Design, Medical record, Information sharing.

\section{INTRODUCTION}

Hospital is institution that held individual health service, such as inpatient, outpatient, and emergency care facilities [1]. Hospital prepared complete medical tools and infrastructure to give the best medical service for patient. So then, the patient hoped to be recovery as soon as possible and satisfied to the service. In other side, Hospital will get an economical benefit and good image for give a best service to the patients.

There are many social interactions in hospital, such as interaction between patient, doctor, nurse, hospital staff, or another people in hospital. Many social interactions make many activities and surely there are many problems in hospital. Sometime, patient went to hospital not only to consult with the doctor, but also to ask for medical record for many interest. The medical data record can only be accessed if patient ask for it in hospital and to get it, patient have to passes long procedural step. In addition, the lack of hospital care during treatment and consultation are pre-and posttreatment at the hospital where consultations have to face to face with the doctor, although in some cases the disease in the lightweight category. In another case, the patient needs a medium to share about their health problem.

Currently, social network website technology is growing very rapidly. By join it, user able to connect to other users, create personal profile, and make online social network [2]. Personal profile used to get information about another user. It would avoid user to meet strangers in their social network. In addition, users enable to share anything happen and view update from their social network [3].Through the technology could be built a social network system between the parties concerned in the hospital. Matters related to the communication or social interaction between patients and doctor to do with internet media, such as consultations on the symptoms they experienced so that they could take action earlier. In addition to the web, medical records can be safety accessed from the house and printed in the form of reports so that the patient does not need to come to the hospital immediately to look or ask for medical record.

Social network website can be applied for hospital communities. With that website, communication and many lack of hospital can be managed. It types of website need a good database design. So, in this paper the studied will be focus on database design of social network website for hospital community. The database that designed can be basic or references to make more complex social network website then.

\section{THEORITICAL BACKGROUND}

\subsection{Electronic Medical Record}

Medical record is files that contained document and notes about medical service which applied in health facility, such as patient identity, health record, and the other [4]. Formerly, medical record data was traditional (hand-writing documentation) which had many disadvantages and often failed to fulfill many of the tasks demanded from this record, such as caused many hardcopy documents, ineffective operational procedures, and many more[5]. Now, medical data record designed with electronics technology such as web or desktop based which make it easier and more effective. It was namely Electronics Medical Records (EMR). In the EMR, patient data stored as some data type, such as searchable text and numbers or in some case it will stored as document images [6]. Although it was computerize system, the content of medical record may not be changed. World Health Organization (WHO) in Gondodiputro's [7] research explained that generally, information in patient medical record must be contained:

1) Who is the patient, and who was the person who give medical service. For example Made Sukarsa (who), Dr. Arya Sasmita (who give medical service)

2) What, when, why, and how medical service applied. For example, standard check-up (what), $1^{\text {st }}$ January 2012 (when), Patient sighed that he/she was got fever (why), checked-up the temperature of patient body (how).

3) Outcome from medical service, such as medical record, next check up schedule in outpatient case, and the other 
Medical record used as references for the next medical treatment to the patients. By reviewed medical record, doctor could make appropriate decision for next medical care to the patients.

\subsection{Database, E-R Model, and \\ Normalization}

This research was conducted within the scope was the analysis of detail design and development of a database. Database is collection of relational data [8]. The basic concept of the database is a collection of records, or pieces of knowledge. A structured database has a description of the kinds of facts that are stored in it: an explanation is called schema. Scheme describe the object, represented a database, and the relationships between objects. There are many ways to organize the scheme, or modeling the database structure: these are known as the model database or data model. Models are commonly used today is the relational model, which in layman terms represent all the information in the form of tables that are interconnected with each table consists of rows and columns (the true definition uses mathematical terminology). In this model, the relationship between tables represented premises using the same values between tables. Other models such as the hierarchical model and the network model use a more explicit way to represent relationships between tables. Utilization databases for data management also has other purposes as follows [9]: speed and ease, the efficiency of storage space (space), accuracy, availability, completeness, security, usage togetherness (share ability)

Data models are commonly used in the design of information systems first level, for example to describe the information needs and the type of information to be stored in the database for analysis. Entity Relationship Model or E-R Model, known as Entity Relationship Diagram (ERD) is a data model or diagram for high-level descriptions of conceptual data model. ERD provides a graphical notation for representing conceptual data models in the form of an Entity Relationship Diagram. By designed The E-R model, system designer able to mapping the meanings and interactions of real-world enterprises onto a conceptual schema [6].ERD uses a number notation and symbols to describe the structure and relationship between data, including:

a) Entity

An entity is a person, place, object, event (event) or concepts within the user organization / company maintained its data.

\section{b) Attribute}

Attributes are the properties or characteristics possessed by an entity in which the property or characteristic it means / meant for the organization / company. For example, for recording student data in a hospital, the user entity may have attributes Id_patient, Name, Address, Telp_no, and another.

\section{c) Relation}

Relationships are the glue that unifies the different components in the ERD. Intuitively, it can be said that the relation is an association of one or more entities that are meaningful to the organization / company.

In ERD, there is important phase. It is mapping cardinalities and normalization. The relationship between numbers of entities could be associated via relationship set by mapping cardinalities or cardinality ratio [10]. For example, sets $\mathrm{X}$ and $\mathrm{Y}$ which each of it had some entity, the mapping cardinality must be one of the following [10]: a) One-to-one

An entity in $\mathrm{X}$ is related with at most one entity in $\mathrm{Y}$, and an entity $\mathrm{Y}$ is related with at most one entity in $\mathrm{X}$.

b) One-to-many

An entity in $X$ is related with any number (zero or more) or entities in Y. An entity in Y, however, can be related with most one entity in $\mathrm{X}$.

c) Many-to-one

An entity in $X$ is related with at most one entity in B. An entity in B, however, can be related with any number (zero or more) of entities in A.

d) Many-to-many

An entity in $X$ is related with any number (zero or more) of entities in $\mathrm{Y}$, and an entity in $\mathrm{X}$ is related with one number (zero or more) of entities in $\mathrm{X}$.

Normalization process is method for designing a relational database to generate a set of relation schemas and minimize unnecessary redundancy [10]. Normalization process can break up big schema of database into smaller schema. It is useful to make database access work faster and more efficiency.

The result of ERD process, including normalization and cardinality ratio, is a efficiency schema of database. Then, that schema will applied in database design.

Generally, in all application, including social network website, there are user. Figure 1 show the attribute of user entities:

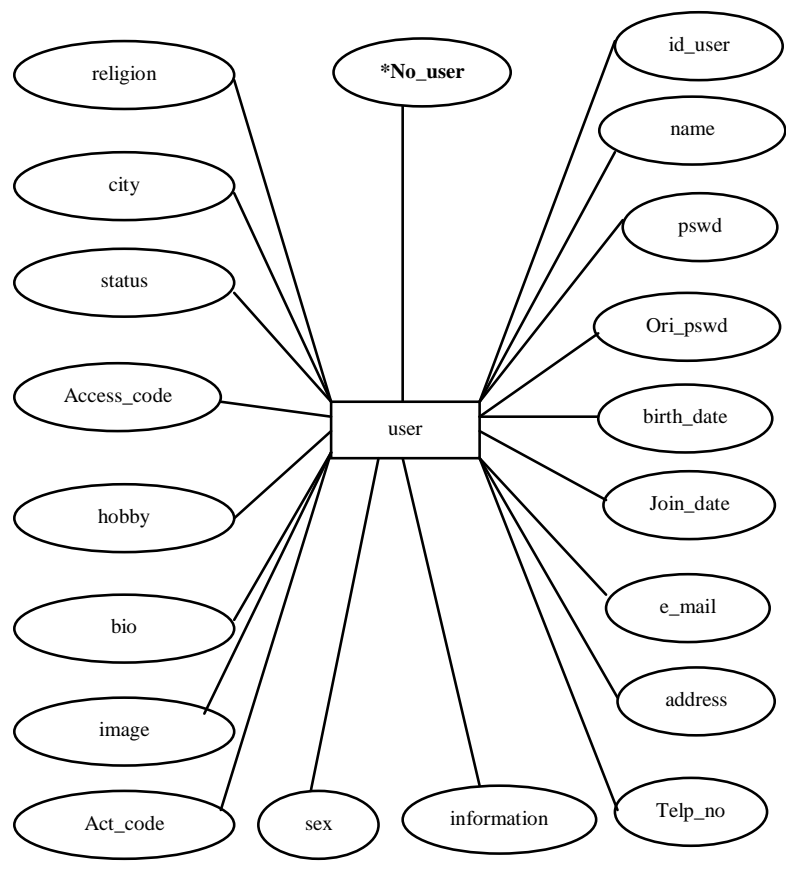

Fig 1: Attribute of user entities

To make easier, in next explanation, user entities and it attributes named "X". User entity primary key is no_user. All of the attributes applied in database as field of table. In user entities there are many attribute that can be separated to be the new entity / table. The process to make a new entity from existing attributes called normalization. For example, figure 2 show the normalization process between user and sex. 


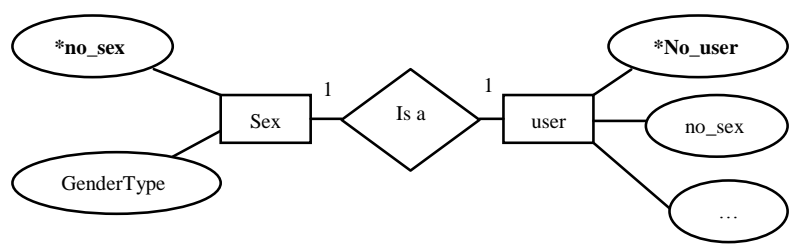

Fig 2: Normalization between user entity and sex

Sex is attributes of user. But when it was become a table, the sex field will be filled by redundant contents, it is "Male" or "Female". "Male" and "Female" can be replaced by "0" and "1" that could make database access work faster. So, sex attribute separated to be new entity named "Sex" and no_sex become primary key of that entity. In X, sex field become new field named no_sex. Then, no_sex of user entity is foreign key to sex entity. Figure 2 could be read as "user is a [sex]", like "Jhony is a Male".Normalization process is considerate cardinalities ratio too. Figure 3 show one-to-one cardinality ratio, so it can be separated as new entity.

With same normalization process used ERD, there will become many new entity that applied as table then. The table results of all normalization are: user, sex, religion, city, access, status, and activation. User also do many activity in social network web like post something to the web, give a comment to other user post, send a messages to other user, and other activity. That activity patched to the new entity / table, like post_table, messages_table, group_table and another. That new entity / table have many attributes. With same normalization process, it will make many new entities.

\subsection{Related Reserach}

There is earlier research about social network web. Mardiyanto et al[11] has conducted similar research, entitled "Rancang Bangun Website Pertemanan Menggunakan Ajax Framework Untuk Komunitas PJJ" or in English "Design of Social Website Build Ajax Framework For PJJ Community". The methodology that used in this research is the study of literature, application design, application creation, Test and evaluation, and preparation of final book. Result: with the first data set in the database then it is expected to minimize the user who is not a student PJJ to enter into the application, the simplicity of the existing facilities in this application is sufficient to meet basic needs as friendship sites that allow user to seek and acquire new friends and can further recognize users who have had friendly relations with the user, and communication needs are realized in the form of testimonials and comments on the status of the user that there could be one adhesive sense of community among existing users.

This research also inspired by research of Prastowo[12], entitled "Pengembangan Sistem Paperless Office Berbasis Sistem Jejaring Sosial" or in English "Paperless Office System Development Based on Social Network System". The research studied about a system which could make activity in office more effective and minimized use of paper. In addition, there some research about Electronic medical record (EMR) and Hospital Management and Information System (HMIS) $[4,5,6,7]$ which was be references of this research too.
Table 1. Comparative study of related social network sites research

\begin{tabular}{|c|c|c|}
\hline Feature & Related Research & Our Research \\
\hline Post & $\checkmark$ & $\checkmark$ \\
\hline Comment & $\checkmark$ & $\checkmark$ \\
\hline $\begin{array}{l}\text { Friends (request } \\
\text { /accept/ ignore) }\end{array}$ & $\checkmark$ & $\checkmark$ \\
\hline $\begin{array}{c}\text { Messages (Wall / } \\
\text { Personal Messages) }\end{array}$ & $\checkmark$ & $\checkmark$ \\
\hline Photo Management & $\checkmark$ & $\checkmark$ \\
\hline Wiki & - & $\checkmark$ \\
\hline Information Sharing & $\checkmark$ & $\checkmark$ \\
\hline $\begin{array}{l}\text { Type } \\
\text { Information } \\
\text { sharing }\end{array}$ & $\begin{array}{l}\text { Paperless Office } \\
{[12]}\end{array}$ & $\begin{array}{l}\text { Hospital } \\
\text { Information } \\
\text { Sharing }\end{array}$ \\
\hline $\begin{array}{l}\text { Level of } \\
\text { Information } \\
\text { sharing }\end{array}$ & File sharing & $\begin{array}{l}\text { Database } \\
\text { operation }\end{array}$ \\
\hline
\end{tabular}

Table 1 show the comparative between this research and related social network sites research. As general social network site design, design of system in this research had standard feature of social network, such as post, comment, friends, messages, and photo management. The new features of this research are Wiki and Hospital Information sharing.

Table 2. Comparative study of related Hospital Management and Information System (HMIS) and Electronic Medical Record (EMR) research

\begin{tabular}{|l|c|c|}
\hline \multicolumn{1}{|c|}{ Feature } & Related research & Our Research \\
\hline $\begin{array}{l}\text { Complex General } \\
\text { HMIS / EMR } \\
\text { feature }\end{array}$ & $\checkmark$ & - \\
\hline $\begin{array}{l}\text { Hospital } \\
\text { Information } \\
\text { sharing to Social } \\
\text { Network sites }\end{array}$ & & \\
\hline
\end{tabular}

Table 2 show the comparative between this research and related Hospital Management and Information System (HMIS) and Electronic Medical Record (EMR) research. This research focused on Hospital Information sharing ability, so the design of system in this research had no complex feature as General HMIS or EMR. The system designed to sharing EMR of hospital information only. So, user enable to view their medical record in their personal account.

Based and inspired by that related research and watched how social media be a trend, in this paper, the object of research is Hospital community. In addition, this paper is focused to database design detail. Social network website that designed not only for shared status, comment one and other users post, messaging, and other activity like a general social network, but also there are Medical Record and Wikipedia menu in this database design as a value added of this social network and new value of research. This database design will designed to mix social network and little part of hospital information system. 


\section{SYSTEM OVERVIEW}

Network data are defined by actors and by relations (nodes, ties, or another) [13]. The nodes or actors part of network data would seem to be pretty straight-forward. Every social network web has many features, but basically, main feature of social network feature are posted, commented, messages, and group (joined, posted, and commented). The Hospital information system has many features. One of it was medical data record.

The system which designed was able to handle medical record data from many hospitals. The general system design to handle it, as follows:

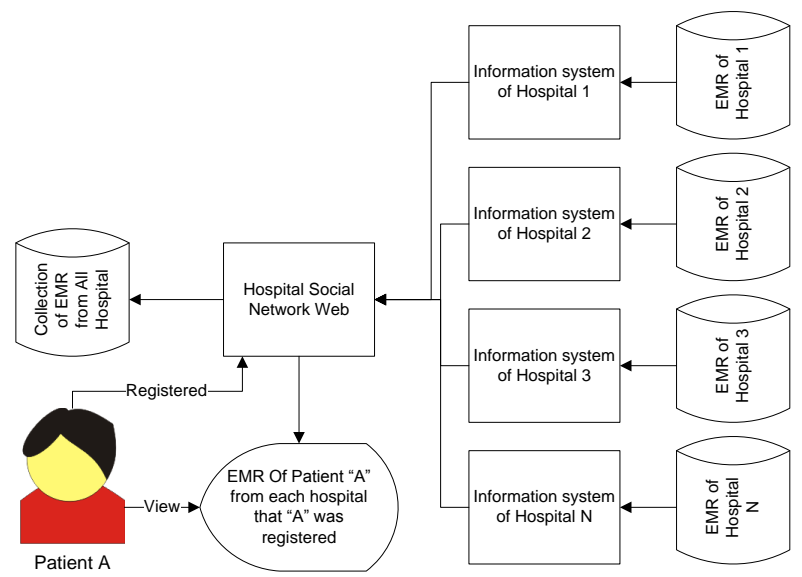

Fig 3: General design of EMR data from Multi-hospitals

Every hospital had Information System. Electronic medical record (EMR) database from each Information system of hospital clustered into one database in Hospital social network web. So, if standard-user (patient) was registered in more than one hospital, patient able to viewed the medical record from each hospital where the patient has registered.

Social network web which designed based on user activity in the nodes, combination of social network and little part of hospital information system, such as posted, commented, join group, view medical record, published wiki, requested / accepted / ignored friend, and send messages. The general concepts of this social network website are as follows:

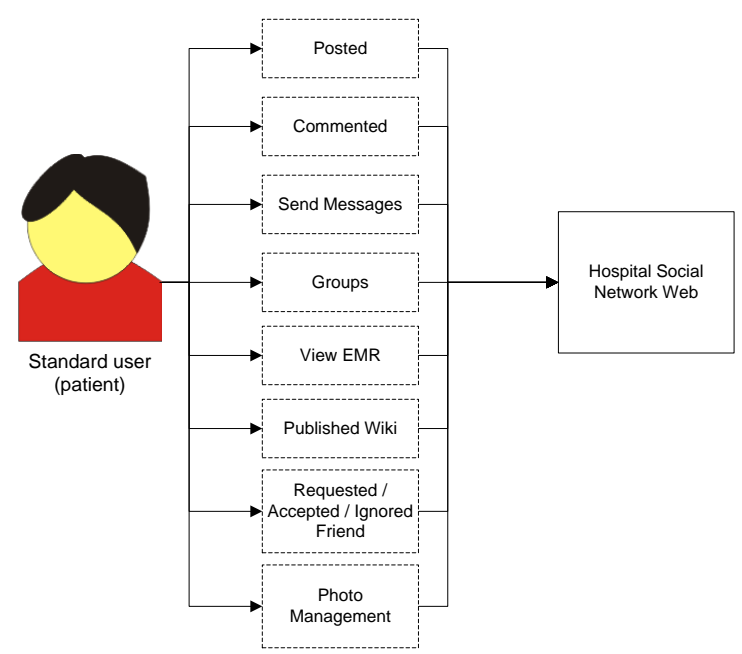

Fig 4: General Schema of user activity
If patient has registered in Hospital social network, patient able to do activity as showed in figure 4 .

\section{DATABASE AND USER-INTERFACE DESIGN}

\subsection{Database Design}

1) User and related table

Like a general design of application database, the design of social network database hospitals are also commonly used tables are often used, such as the user table with the results of normalization, such as gender tables, city table, religion table, and another. The design of this database is devoted to hospital community, for it is also added to the user table fields that associated with hospital, then normalized later in the form of tables, such as member tables and hospital table. Social network philosophy ensured that the site able to meets the needs of end users, such as active, dynamic, and userdriven[14]. The analysis of social network focuses on the relations of entity in social or organizational system [15]. If drawn, the design of the user and related database are as follows:

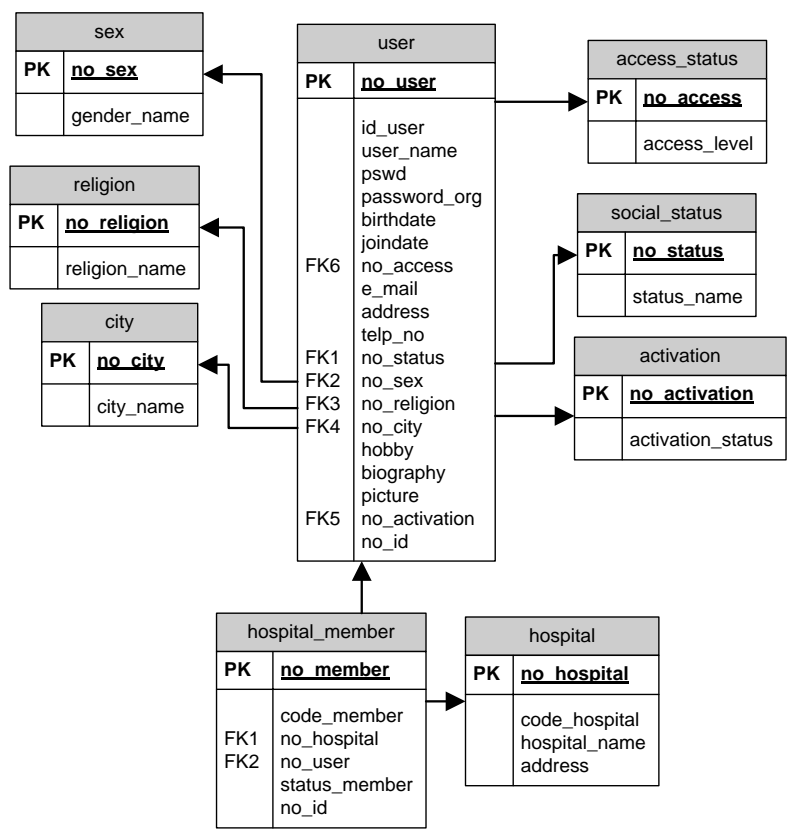

Fig 5: The design of user and related table

User table should be created as many as user type. For example, there are three type of user, such as doctor, patient, and nurse. In that case, it was better to created three table, namely doctor_table, patient_table, and nurse_table. In other ways, if system designed to used one user table, it better to add unique field to difference each type of user.

Based on the observation and study of literature, design of social network database was unique. Uniqueness is the existence of tables that are used to connect users to one another, namely:

2) Friendship and related table

Table of friendship used to connect users to one another, so that if a user has not made friends connection with another user then the user is not able to communicate, access data or perform an activity with other users, for example: User $\mathrm{x}$ has not made friends connect with user $\mathrm{Y}$, the user $\mathrm{X}$ unable to 
comment on posts made by user $\mathrm{Y}$, and vice versa. Here is the picture:

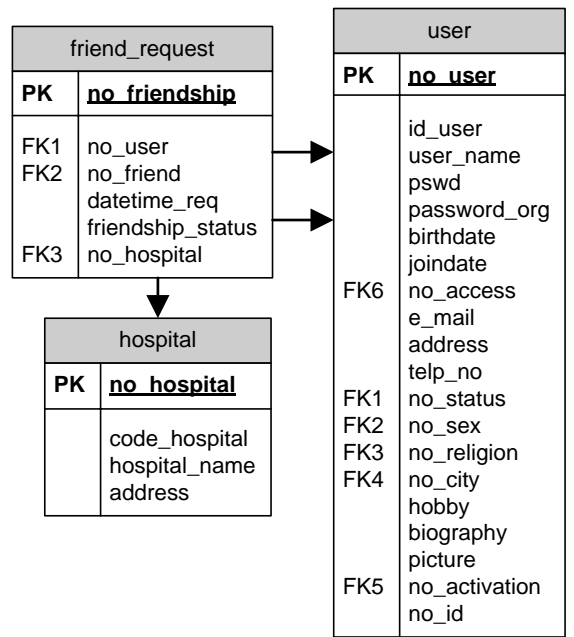

Fig 6: The design of friendship and related table

3) Groups and related table

Group table is used to connect users to one another in a group or groups. In addition, In Groups, user able to posted and commented too, so group_post and group_comment table created too as storage.

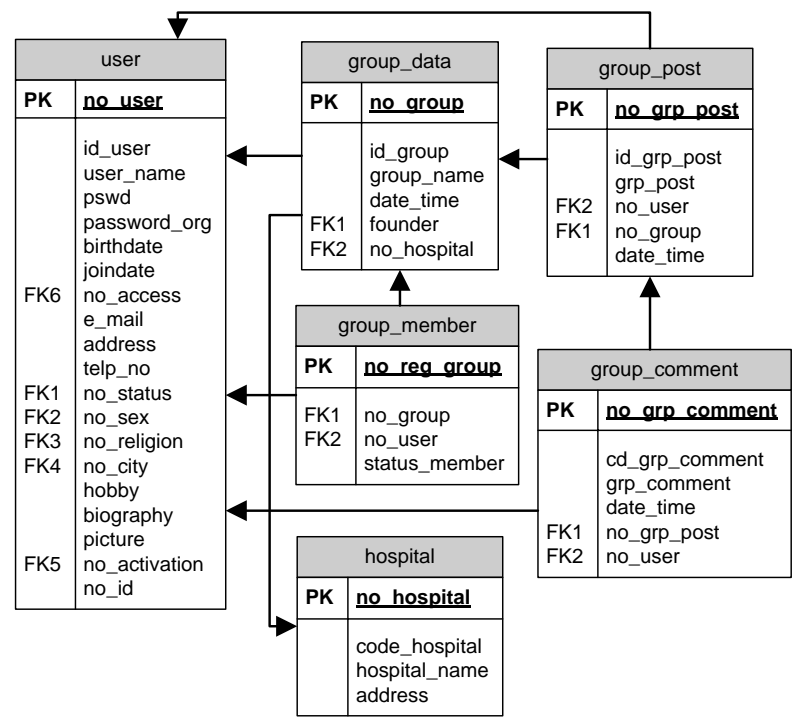

Fig 7: The design of groups and related table

In addition, there is also a table that is used to connect the user and the other one related to the activity in the application, such as the post table, category table, table comment, message tables, and the other

4) Post and related table

The table used for the storage of post (some word or sentence typed by a user to be distributed to other users) data. A post is categorized under a well established category so category table must be created as data storage. User enable to commented on the post. So, table of comments created for the storage of the comments data given by the user to the post of other users.

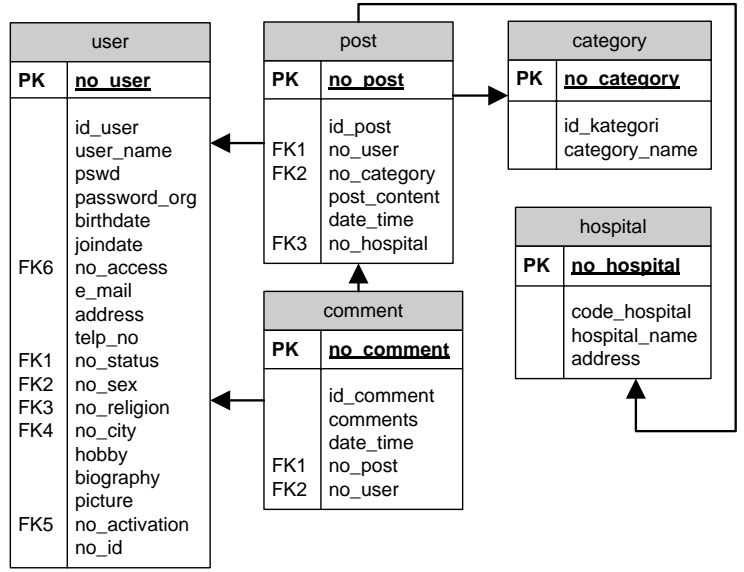

Fig 8: The design of post and related table

5) Messages and related table

Message table used for the storage of data relating to personal messages sent between users. Besides being sent messages can be commented upon, so comment of messages table must be created as data storage.

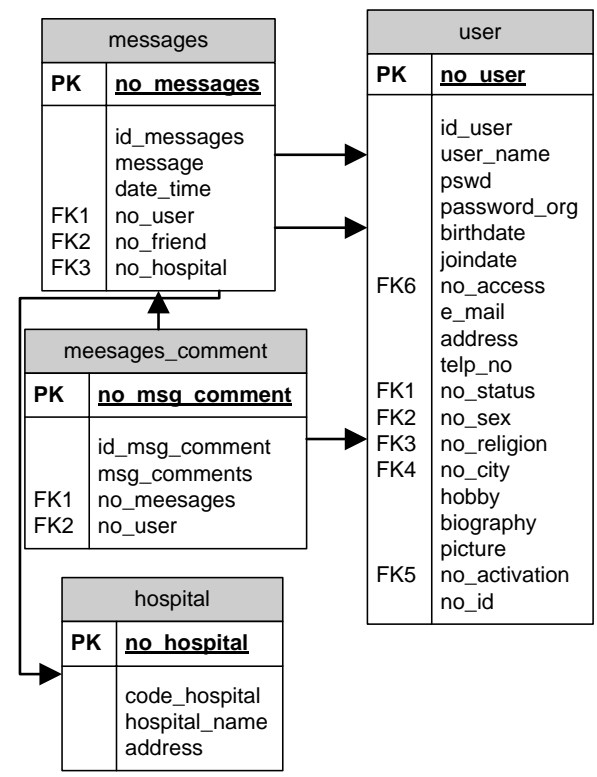

Fig 9: The design of message and related table

6) Medical Record and related table

Social network built for the Hospital community, for it can be formed of a table that reflects the hallmark Hospital. Tables can be formed in this case is the medical record chart. Tables medical records used for the storage of data relating to the records of a user record medic. Here is a picture related to the design table record medic: 


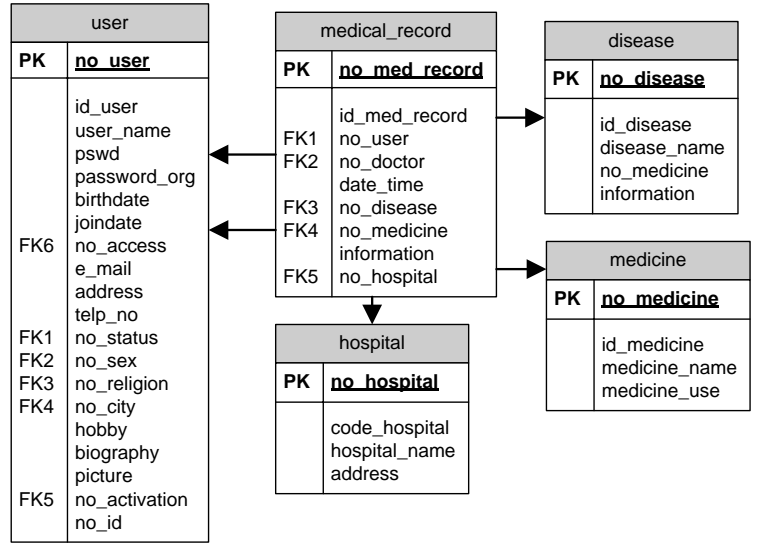

Fig 10: The design of medical record and related table

In other ways, medical record and related table is not need to be created where the hospital had medical record database in existing HMIS or EMR. System was enables to get the data from it by build web service or other method.

7) Wiki and related table

Wiki table created for storage of Wikipedia or knowledge information data that published by user. The topic of knowledge is about Hospital and healthy, here is a picture of the database design:

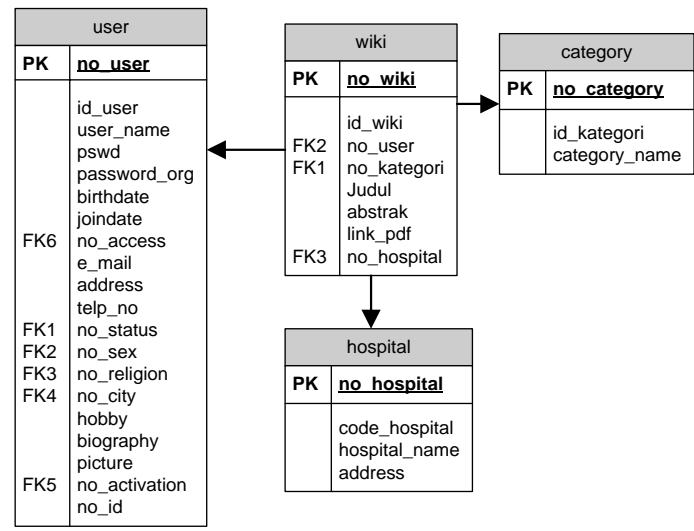

Fig 11: The design of Wiki and related table

8) Photo and related table

Photo and related table created as storage of photo of user and all activities that related to it, such as photo album, and comments.

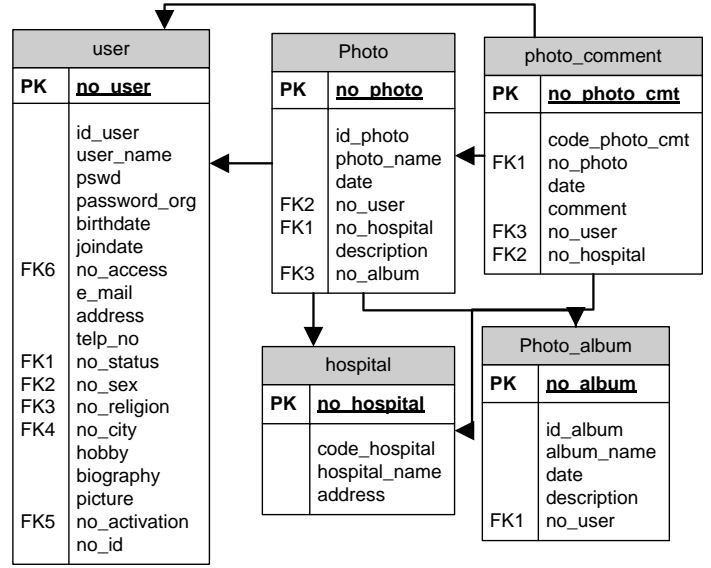

Fig 12: The design of Photo and related table
9) Notification Table

There are many activity of user in the web, such as posting, commented, requested friend, and the other. Notification used to give notification to user for activity of another user that related to his/hers. For example, user x commented to user y post. In user y interface, will be showed a notification that user $\mathrm{x}$ commented in her/his post. It was the function of notification table. The content of "Type" field in notification table is numeric which symbolize a type of notification.

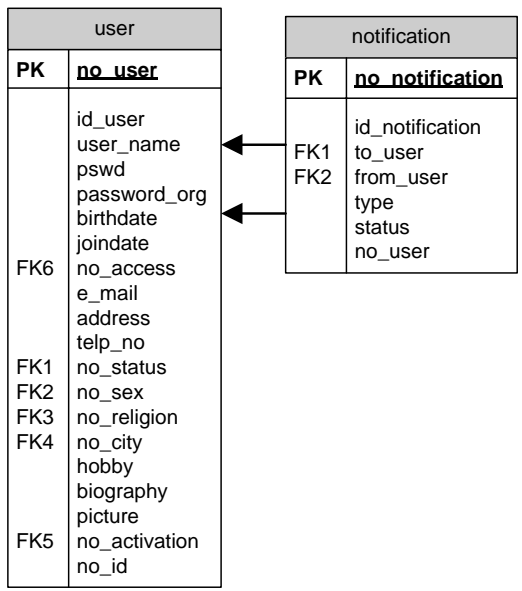

Fig 13: The design of notification table

\subsection{User Interface Design}

The user-interface design show as follow:

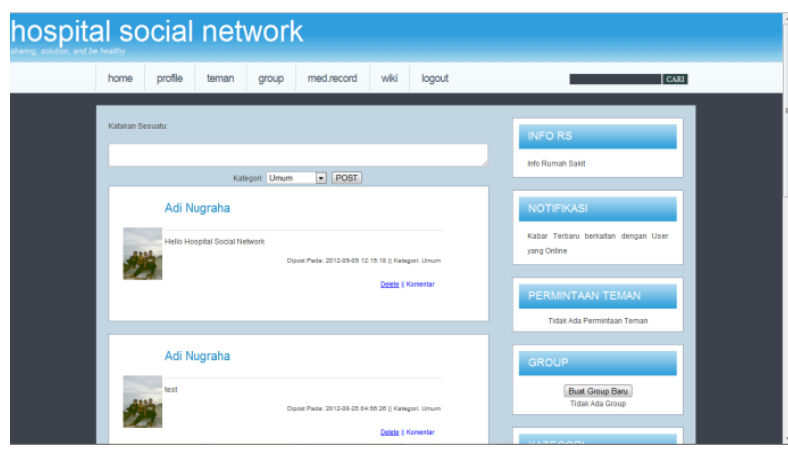

Fig 14: User-interface of standard user

As a regular web design, first page is Login page. After it, Fig 14 shows a home page of standard user (patient) userinterface:

1) Home

Show main menu of the web, especially post of user. In addition, there are notification, friend request, group list, and the other.

2) Profile

Show the information about the user

3) Friend

This page showed friend of user. User able to requested friend to other user and accepted or rejected friend request from other user 
4) Group

Show the group which was joined by user. User able to created group, posted, and commented on group.

5) Medical Record

Show the medical record of user. Electronic medical data records data input by admin. Standard-user, such as patient, allows to viewed it only

\section{6) Wiki}

Show wiki that shared by another user which has checked and accepted by admin user.

\section{CONCLUSION}

From the analysis in the previous section, it can be concluded as follows:

1) The design of social network database for hospital successfully created. The design able to handle Electronic medical record (EMR) from many hospitals into one media (social network sites).

2) In the design of social network database, there are several tables that became the core of the application / social network sites. That is the table which used for the framing of user with other users, such as the friendship and group table. In addition, in the design of these networks sites there are also database tables for the data storage and other single user activity.

3) There was uniqueness in the design of social network database for hospital, which is a table of medical record that the data used for the storage of user medical records. In other ways, medical record and related table is not need to be created where the hospital had medical record database in existing HMIS or EMR. System was enables to get the data from it by build web service or other method.

4) The new features of this research are: Wiki and Hospital Information sharing in the social network sites and system enable to view EMR from multi-hospital.

\section{REFERENCES}

[1] Departemen Kesehatan Republik Indonesia. 2009. Ketentuan Umum. Indonesia: Departemen Kesehatan Republik Indonesia.

[2] Stroud, Dick. 2007. Social network: An Age-neutral Commodity - Social network becomes a mature web application. Journal of Direct, Data, and Digital Marketing Practice; 9(3): 278 - 292.
[3] Boyd, Danah M., Ellison, Nicole B. 2007. Social Network Sites: Definition, History and Scholarship Indiana: Journal Of Computer-Mediated Communication

[4] Murdani, Eti. 2007. Pengembangan Sistem Informasi Rekam Medis Rawat Jalan Untuk Mendukung Evaluasi Pelayanan di RSU Bina Kasih Ambarawa. Semarang: Universitas Diponegoro.

[5] Peng, Thomas C.C., et al. 1992. An Integrated, Hospital Information System Based Obstetrical Medical record and Database. Virginia: Medical College of Virginia/ Virginia Commonwealth University.

[6] Laerum, Hallvard., Karslen, Tom H., Faxvaag, Arild. 2003. Use of and attitudes to a hospital information system by medical secretaries, nurses and physicians deprived of the paper-based medical record. A case report. Norway: Norwegian University of Science and Technology.

[7] Gondodiputro, Sharon. 2007.Rekam Medis dan Sistem Informasi Kesehatan di Pelayanan Primer Kesehatan (Puskesmas). Bandung: Universitas Padjajaran.

[8] Kadir, Abdul. 2008. Belajar Database Menggunakan MySQL. Yogyakarta: CV.ANDI OFFSET.

[9] Fathansyah. 1999. Basis Data. Bandung: Informatika.

[10] Silberschatz, Abraham., Korth, Henry F., Sudarshan, S. 2009. Database System Concepts. Sixth Edition. New York: McGraw-Hill.

[11] Mardiyanto, S., Setiowati, Yuliana., Asmara, Rengga. 2010.Rancang Bangun Website Pertemanan Menggunakan Ajax Framework Untuk Komunitas PJJ. Surabaya: Postgraduate PENS ITS

[12] Prastowo, Bambang Nurcahyo. 2009.Pengembangan Sistem Paperless Office Berbasis Sistem Jejaring Sosial. Yogyakarta: Universitas Gadjah Mada.

[13] Hanneman, Robert A. 2012. Introduction to Social Network Method. California: University of California.

[14] Conole, Grainne., Culver, J., Williams, P., Cross, S., Clark, P., Brasher, A. 2008. Cloudworks: Social network for learning design. Ascilite. Melbourne. 2008: 187 196.

[15] Tsvetovat, M., Diesner, Jana., Carley, M. Carley, Kathleen. 2005. NetIntel: A Database for Manipulation of Rich Social Network Data. Pittsburgh: Carnegie Mellon University. 